\title{
Numerical simulation of scour infilling in overset grid
}

\author{
H. Kim, H.C. Chen \& J.-L. Briaud \\ Texas A\&M University, College Station, Texas, USA
}

\begin{abstract}
In the present study, sediment transport models have been implemented in the CFD solver FANS3D to simulate scour infilling process around a circular pier. FANS3D uses the finite-analytic method, which incorporates the analytic solution of the differential equation in its linearized form in the respective small subdomain. The Reynolds-Averaged Navier-Stokes equations are solved in general curvilinear coordinate system. The Chimera overset grid technique is utilized to simulate flows in a multi-block domain. This paper presents the time development of the scour hole and the infilling process due to bed load transport of non-cohesive sediment under the three flow conditions: flood, normal, and flood-to-normal transitional. The effect of the size of the sediment particle is also discussed.
\end{abstract}

\section{INTRODUCTION}

\subsection{Motivation}

Understanding the process of scour infilling is of a great importance in the field of civil engineering. As scour depth is often measured after storm events, the observation may not represent the maximum scour depth in the presence of infilling (Foti \& Sabia, 2014). In order for the engineers to obtain the actual maximum scour depth, as opposed to the infilled depth, numerical simulation will be the most viable option in terms of cost and effort.

\subsection{Existing research on scour simulation}

Historically, most numerical studies on scour around structures were conducted under a constant flow environment. Roulund et al. (2005) investigated the flow and scour around a circular pile with experimental and numerical means. They measured the flow characteristics on both rigid and mobile bed, and compared with the simulated results. Escauriaza and Sotiropoulos (2011) studied the bed forms during the initial stages of scour. The work by Khosronejad et al. (2012) involved piers of different shapes: cylinder, square, and diamond. A constant flow velocity was used for each case. An empirical formula by Jia et al. (2002) was incorporated in their model to capture the increase in shear stress in the leading edge of the pier. On the other hand, Dixen et al. (2013) reported their numerical and experimental investigation of scour around a half-buried sphere.
They developed an algorithm to account for the effect of external turbulence on the bed, thereby improving the accuracy of their morphologic model.

Only recently, the scour infilling around a pier was investigated using a fully-coupled hydrodynamic and morphologic model by Sumer et al. (2014). Both suspended and bed loads under an oscillatory wave flow were considered. Ahamd et al. (2015) simulated wave scour around two and three piles. The backward and forward wave action produced infilling.

\subsection{Scope of the present work}

The objective of the authors was to test the capability of the current computational fluid dynamics (CFD) model, FANS3D (Finite-Analytic NavierStokes code for 3D flow), to simulate scour infilling. This was achieved by adopting three different hydrographs as the mean flow velocity conditions: flood, normal, and flood-to-normal transitional. The time series of the maximum scour depths for the aforementioned conditions are presented. In addition, a parametric study of the sediment particle size was conducted to analyze its effect on infilling evolution. For the current study, only bed load model was incorporated. 


\section{HYDRORYNAMIC MODEL}

\subsection{Governing equations}

FANS3D solves three-dimensional unsteady, incompressible Reynolds-Averaged Navier-Stokes (RANS) equations. In tensor notation, the governing equations are as follows (Wu et al, 2000):

$\frac{\partial u_{j}}{\partial x_{j}}=0$

$\frac{\partial u_{i}}{\partial t}+\frac{\partial\left(u_{i} u_{j}\right)}{\partial x_{j}}=-\frac{1}{\rho} \frac{\partial p}{\partial x_{i}}+\frac{1}{\rho} \frac{\partial \tau_{i j}}{\partial x_{j}}+F_{i}$,

where $u_{i}=$ mean velocities; $\rho=$ fluid density; $p=$ pressure; $\tau_{i j}=$ deviatoric stresses; and $F_{i}=$ external force such as one due to the gravitation. The deviatoric stresses are defined by the following equation:

$\tau_{i j}=\rho\left(v+v_{t}\right)\left(\frac{\partial u_{i}}{\partial x_{j}}+\frac{\partial u_{j}}{\partial x_{i}}\right)-\frac{2}{3} \delta_{i j} k$,

where $v=$ kinematic viscosity; $v_{t}=$ eddy viscosity; $\delta_{i j}=$ Kronecker delta; and $k=$ turbulent kinetic energy.

In the current study the standard $k-\varepsilon$ model by Rodi (1993) is used for turbulence closure and the eddy viscosity is calculated with:

$v_{t}=c_{\mu} \frac{k^{2}}{\varepsilon}$

The turbulent kinetic energy $k$ and the dissipation rate $\varepsilon$ are determined from Eqs. (5) and (6), respectively.

$\frac{\partial k}{\partial t}+\frac{\partial\left(u_{j} k\right)}{\partial x_{j}}=\frac{\partial}{\partial x_{j}}\left[\left(v+\frac{v_{t}}{\sigma_{k}}\right) \frac{\partial k}{\partial x_{j}}\right]+G-\varepsilon$

$\frac{\partial \varepsilon}{\partial t}+\frac{\partial\left(u_{j} \varepsilon\right)}{\partial x_{j}}$

$=\frac{\partial}{\partial x_{j}}\left[\left(v+\frac{v_{t}}{\sigma_{\varepsilon}}\right) \frac{\partial \varepsilon}{\partial x_{j}}\right]+\left(c_{\epsilon 1} G-c_{\epsilon 2} \varepsilon\right) \frac{\varepsilon}{k}$,

where $G=$ production of $k$. The terms $\sigma_{k}, \sigma_{\varepsilon}, c_{\mu}$, $c_{\epsilon 1}$, and $c_{\epsilon 2}$ are model coefficients.

\subsection{Wall-function approach}

In order to account for the roughness effects of the sediment particles on the bed surface, the wallfunction is adopted. As outlined in $\mathrm{Wu}$ et al. (2000), the first grid point is placed within the logarithmic region. Then, through iterative method, the following relation was enforced to obtain the local shear velocity $u_{\tau}$ :

$\frac{U}{u_{\tau}}=\frac{1}{\kappa} \ln E y^{+}$,

where $U=$ total velocity parallel to the bed surface; $\kappa=$ von Kármán constant; $y^{+}=$viscous length; and $E=e^{[\kappa(B-\Delta B)]}$. The constant $B$ has the value of 5.2 and $\Delta B$ is determined by Cebeci \& Bradshaw (1977) as a function of the roughness height $k_{s}$. Finally, the kinetic energy $k$ and the dissipation rate $\varepsilon$ at the second grid point are specified by:

$k=\frac{u_{\tau}^{2}}{c_{\mu}^{1 / 2}}$
$\varepsilon=\frac{u_{\tau}^{3}}{\kappa y}$

The roughness height $k_{s}$, which describes the roughness of the bed, plays an important role in numerical modeling of sediment motion, as it affects the velocity profile and the value of $u_{\tau}$. Whereas it is set to zero for smooth surface, values as high as $200 d_{50}$ have been suggested for cases with bedforms (van Rijn 1984), where $d_{50}=$ median particle diameter. In the present study, however, $k_{s}$ was specified to $2 \mathrm{~cm}$ regardless of $d_{50}$ to limit the number of variable parameters.

\section{MORPHOLOGIC MODEL}

The balance of bed load flux within a control volume is modeled with the Exner equation (Fortunado \& Oliviera, 2007):

$\frac{\Delta z}{\Delta t}=\frac{1}{(1-n)} \nabla \cdot q_{b}$

where $\Delta z=$ the bed elevation change over the time step $\Delta t ; n=$ porosity of the sediment; and $q_{b}=$ bed load flux. In Eq. (10) the bed load flux $q_{b}$ is determined following Khosronejad et al. (2011):

$q_{b}=\psi\|d s\| \delta_{B L} u_{B L}$,

with the formulation for the reference concentration by van Rijn (1984):

$\psi=0.015 \frac{d_{50}}{\delta_{B L}} \frac{T^{1.5}}{D_{*}^{0.3}}$,

where $\|d s\|=$ length of the edge of the finite volume; $\delta_{B L}=$ thickness of the bedload layer; $u_{B L}=$ velocity vector at the top of the bedload layer; $T=\mathrm{di}$ mensionless excess shear stress, and $D_{*}=$ dimensionless sediment diameter. The latter two terms are defined as (van Rijn, 1984):

$T=\frac{\tau-\tau_{c r}}{\tau_{c r}}$

$D_{*}=d_{50}\left[\frac{\left(\rho_{s}-\rho\right) g}{v^{2}}\right]^{1 / 3}$,

where $\tau=$ shear stress on the bed surface; $\tau_{c r}=$ critical shear stress; $\rho_{s}=$ density of sediment; and $g=$ gravitational acceleration.

The critical shear stress term in Eq. (13) is computed by multiplying the critical shear stress based on Shields diagram $\left(\tau_{c r 0}\right)$ by a correction factor (Roulund et al. 2005, Khosronejad et al. 2011):

$\tau_{c r}=$ 
$\tau_{c r 0}\left[\cos \beta \sqrt{1-\frac{\sin ^{2} \alpha \tan ^{2} \beta}{\tan ^{2} \phi}}-\frac{\cos \alpha \sin \beta}{\tan \phi}\right]$,

where $\beta=$ local maximum slope; $\alpha=$ angle between the direction of the local maximum slope and the velocity vector at the top of bedload layer; $\phi=$ angle of repose, which is set to $32^{\circ}$.

It is also necessary to ensure that the angle of repose inherent to the sediment type is not exceeded in the domain. Thus, the sand slide correction scheme by Khosronejad et al. (2011) is adopted. The algorithm first computes the slope between a cell $P$ and its neighbors. If any of these slopes exceeds the angle of repose, volumes of sediments are exchanged among the same neighboring cells while maintaining the conservation of mass. The process is formulated by the following equations:

$$
\begin{aligned}
& \frac{\left(z_{b p}+\Delta z_{b p}\right)-\left(z_{b i}+\Delta z_{b i}\right)}{\Delta l_{p i}}=\tan \phi \\
& A_{h p} \Delta z_{b p}-\sum_{i=1}^{4} A_{h i} \Delta z_{b i}=0,
\end{aligned}
$$

where $z_{b p}=$ bed elevation at point $P ; z_{b i}=$ bed elevation at the neighboring cells; $\Delta z_{b p}$ and $\Delta z_{b i}=$ the correction height applied to the aforementioned points, respectively; $\Delta l_{p i}=$ horizontal distance between the point $P$ and its neighbor $i$; and $A_{h p}$ and $A_{h i}=$ the areas of the cells $P$ and $i$, respectively.

As of time of writing, the implementation of the morphologic model is being validated with experimental data, the results from which will be published in the future.

\section{FINITE-ANALYTIC METHOD}

The hydrodynamics is solved with the finite-analytic method in non-staggered, general curvilinear coordinate systems. Developed by Chen \& Chen (1984), it utilizes the analytic solutions of the governing differential equations. Consider a three-dimensional finite-analytic subdomain, as depicted in Fig. 1. In evaluating the governing differential equation for the interior node $P$, an algebraic equation relating the nodal value as a function of the neighboring values is solved. The coefficients involved in the said equation are determined by evaluating the local analytic solution at $P$, obtained by the method of separation of variables. For more detail the reader is referred to Chen \& Chen (1984), Chen et al. (1990), and Chen et al. (2000).

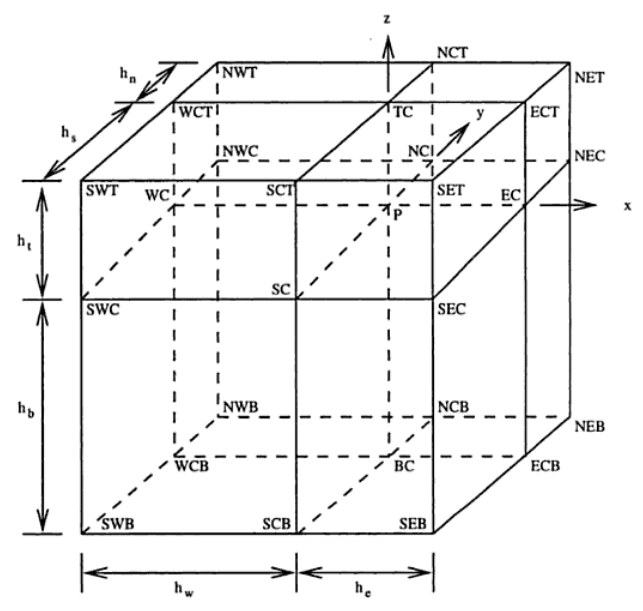

Figure 1. Three-dimensional FA subdomain (Chen et al. 2000)

\section{SIMULATION SETUP}

\subsection{Computational domain}

A three-dimensional computational domain of a cylindrical pier in a channel was generated, as shown in Fig. 2. The domain consists of three overlapping blocks, constructed with overset grid technique. A total around 455,000 grid points were used. The vertical spacing was adjusted for morphologic evolution after every time step.

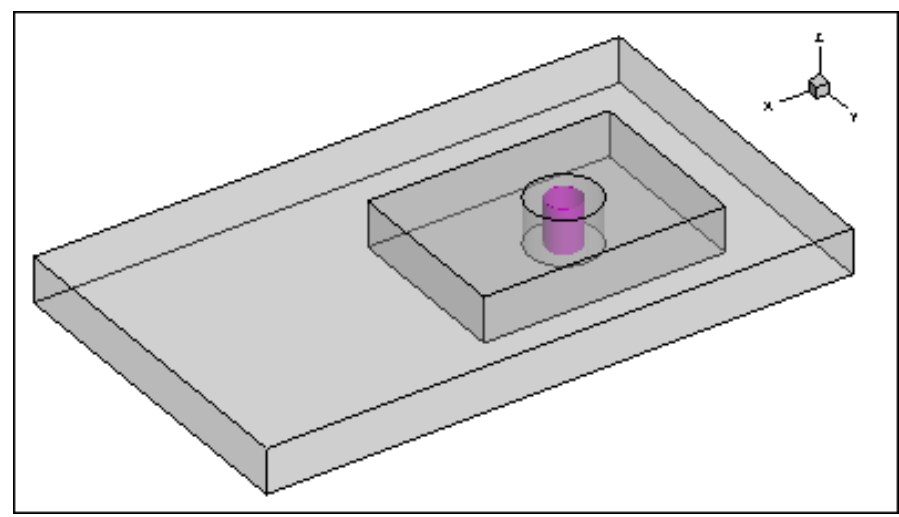

Figure 2. Computational domain used for the simulation, depicting three overlapping blocks.

The diameter $D$ and the height $H$ of the pier are 15 $\mathrm{cm}$ and $20 \mathrm{~cm}$, respectively. The flow regime measures $17 D$ in length and $10 D$ in width.

\subsection{Hydrograph}

Flows with the following three mean velocities were simulated: $0.3 \mathrm{~m} / \mathrm{sec}$ (flood condition), $0.15 \mathrm{~m} / \mathrm{sec}$ (normal condition), and a time-varying hydrograph mimicking the flood followed immediately by the normal flow condition, as shown in Fig. 3.

In the time-varying flow case, the mean velocity was specified to $0.3 \mathrm{~m} / \mathrm{sec}$ initially, which was then reduced to $0.15 \mathrm{~m} / \mathrm{sec}$ after 1 hour of simulated time. The intention of employing such hydrograph was to 
observe the formation of a scour hole around the pier during the initial stage, and allow for infilling to take place.

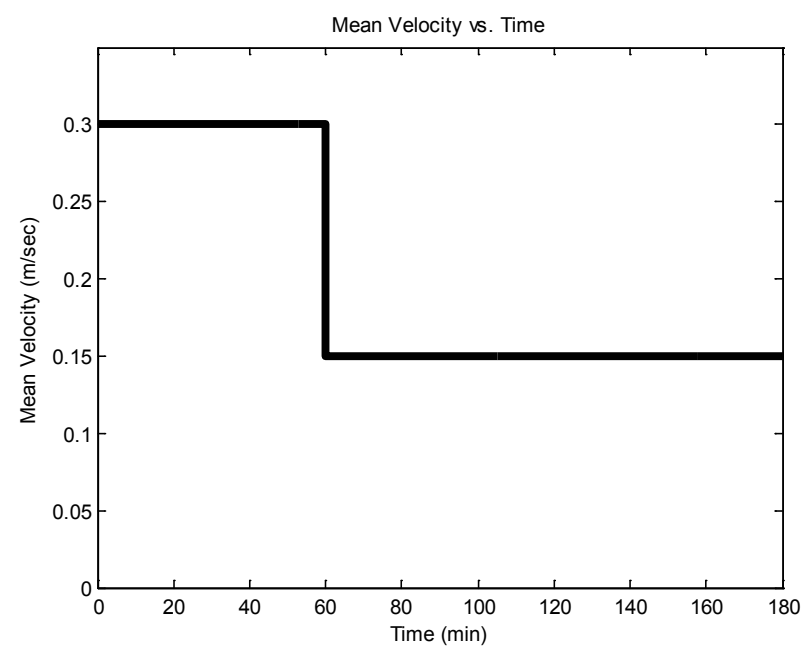

Figure 3. Hydrograph mimicking the flood condition followed by the normal condition.

\subsection{Sediment characteristics}

Two median diameters were employed to test their effects on the morphologic processes: $d_{50}=0.4 \mathrm{~mm}$ and $d_{50}=0.6 \mathrm{~mm}$, both non-cohesive. Porosity $n$ is 0.4 with the density of sediment $\rho_{s}$ is $2,650 \mathrm{~kg} / \mathrm{m}^{3}$.

\section{RESULTS AND DISCUSSION}

\subsection{Hydrodynamics}

The shear stress distributions around the pier under the flood and normal conditions at the onset of scouring are compared in Fig. 4. As shown, the maximum shear stress is found at the position corresponding to $\theta \approx 70^{\circ}$, where $\theta$ is the angle measured from the $x$-axis in the upstream region. This is attributed to the combination of the contraction of streamlines and the presence of horseshoe vortex (Roulund et al. 2005). The critical shear stresses were $0.25 \mathrm{~N} / \mathrm{m}^{2}$ and $0.33 \mathrm{~N} / \mathrm{m}^{2}$ for $d_{50}=0.4 \mathrm{~mm}$ and $d_{50}=0.6 \mathrm{~mm}$, respectively.

\subsection{Scour and infilling}

The maximum scour depths over time for all six cases considered are summarized in Fig. 5. It can be seen that, after 3 hours of simulated time, the cases under the flood and the normal flow conditions were still experiencing scour. On the other hand, infilling process was observed in the cases under the transition flow. The infilling occurred due to the transport of the sediment particles from the upstream with the flow. Equilibrium scour depths were not yet reached.

For all three mean flow conditions, the scour depth corresponding to $d_{50}=0.4 \mathrm{~mm}$ showed higher values of scour depth than $d_{50}=0.6 \mathrm{~mm}$ for the en- tire time domain. This was expected as smaller particles have greater mobility due to the less drag and weight. At the completion of the simulation, the distance between the two flood condition curves $\delta_{f}(t)$ in Fig. 5 was $0.49 \mathrm{~cm}$. Longer simulation time is required to better understand the effects of sediment particle size on the scouring process.
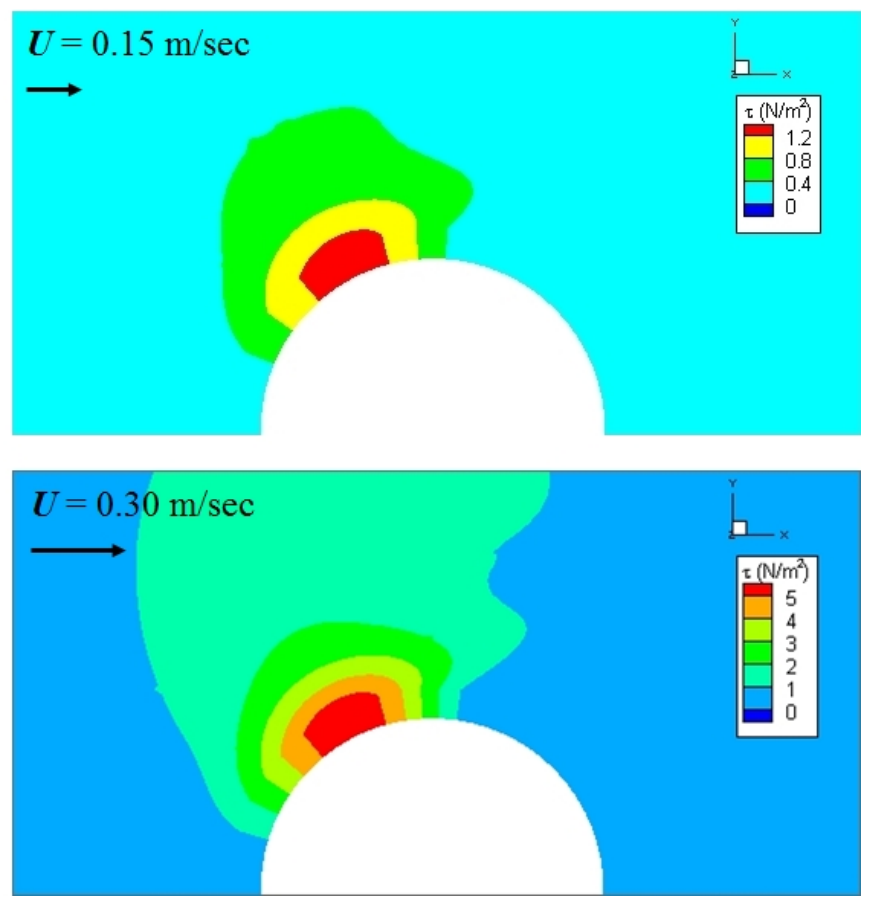

Figure 4. Shear stress distribution around the pier for normal condition (top) and flood condition (bottom).

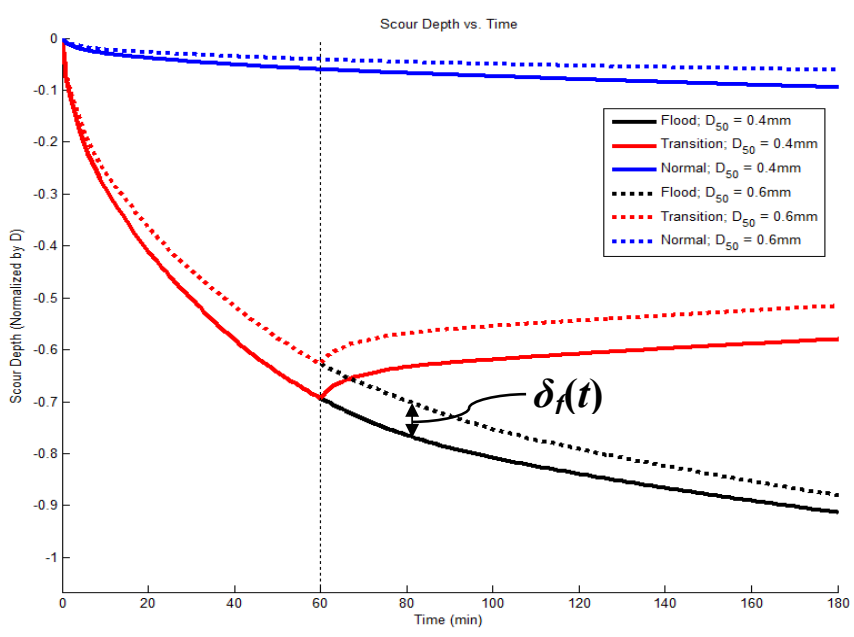

Figure 5. Time series of maximum scour depths.

We now turn the reader's attention to the other four curves in Fig. 5. Sumer et al. (2013) observed that under the flows with the same KeuleganCarpenter number, the equilibrium scour depth of the backfilling process will be same as that of the ordinary scour process (i.e., starting with a flat bed). It is thus expected, with a given $d_{50}$, the curves representing the normal condition and transition flow condition will converge to the same equilibrium depth. 
The distribution of the shear stress for one of the cases after scouring (flood condition; $d_{50}=0.6 \mathrm{~mm}$; time $t=1$ hour) is presented in Fig. 6. Due to the deepening of the bed around the pier, the flow now experiences expansion of area and the maximum shear stress has significantly reduced. In addition, the maximum values are observed as elongated streaks starting from the side of the pier $\left(\theta \approx 90^{\circ} \sim\right.$ $135^{\circ}$ ), as shown in Fig. 6. This can be attributed to the local flow expansion and contraction near the upstream and downstream of the pier, respectively. Grid lines are also plotted to demonstrate the Chimera overset grid technique.

Fig. 7 depicts the three-dimensional view of the computation domain for the same case. Pathlines are plotted to visualize the flow characteristics around the pier.

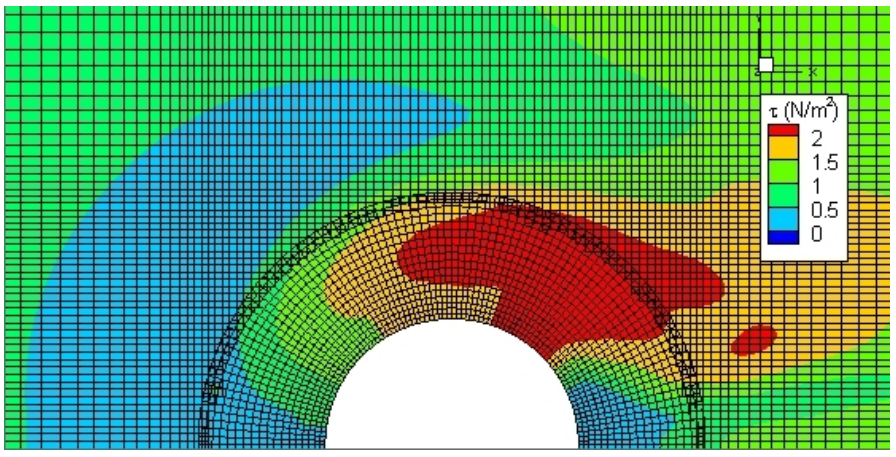

Figure 6. Shear stress distribution after scouring under the flood condition. Flow direction is from left to right.

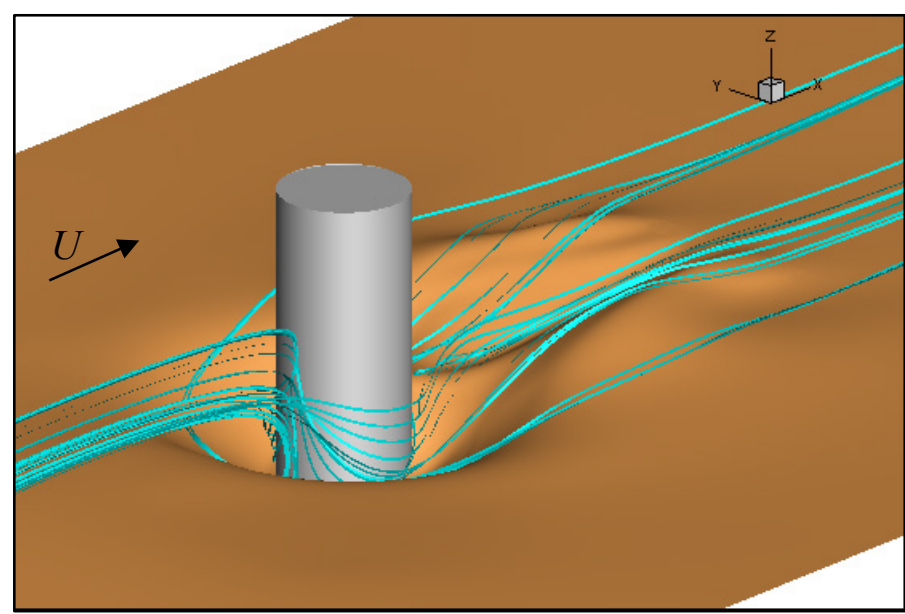

Figure 7. Pathlines around the pier after scouring.

\section{CONCLUSIONS}

The CFD solver FANS3D was coupled with a morphologic model to simulate the flow and bed load transport around a cylindrical pier. Three different mean flow conditions were adopted: constant at 0.3 $\mathrm{m} / \mathrm{sec}$ (flood condition), constant at $0.15 \mathrm{~m} / \mathrm{sec}$ (normal condition), and a time-varying hydrograph in which the flood condition changes to the normal flow after 1 hour. For each flow condition, two different median sediment diameters $(0.40 \mathrm{~mm}$ and $0.60 \mathrm{~mm}$ ) were used to test the effects of particle size on scour and infilling.

The morphologic model was implemented following Khosronejad et al. (2011). The critical shear stress term determined from the Shields diagram was corrected to account for the angle of repose, bed slope, and the direction of the near-bed velocity with respect to the steepest angle. A sand slide scheme was also employed to ensure the angle of repose is not exceeded.

Due to the combined effects of horseshoe vortex and contraction around the structure, the maximum shear stress was found at $\theta \approx 70^{\circ}$ measured from the $x$-axis. This finding is in a good agreement with Roulund et al. (2005).

The morphologic evolution was simulated for 3 hours. The equilibrium scour depth was not reached within the said time frame. Infilling was observed in the transition flow case, in which the scour hole formed during the initial stage (flood condition) was infilled when the mean velocity was reduced to the normal condition. As remarked by Sumer et al. (2013), the equilibrium scour depths for the normal flow and the transition flows will be the same for a given sediment type. We hope to further investigate the fate of the scour holes with longer computation time.

\section{ACKNOWLEDGEMENT}

This investigation was funded by the Massachusetts Department of Transportation. The computational resources were provided by Texas A\&M High Performance Research Computing Facility.

\section{REFERENCES}

Ahmad, N. Bihs, H., Kamath, A. \& Arntsen, Ø.A. 2015. Threedimensional CFD modeling of wave scour around side-byside and triangular arrangement of piles with REEF3D. Proceedings of the 8th International Conference on Asian and Pacific Coasts, Chennai, India

Cebeci, T. \& Bradshaw, P. 1977. Momentum transfer in boundary layers. Hemisphere, Washington, D.C., USA

Chen, C.J., Bernatz, R., Carlson K.D. \& Lin, W. 2000. Finite analytic method in flows and heat transfer. CRC Press, New York, NY, USA.

Chen, C.J. \& Chen, H.C. 1984. Finite analytic numerical method for unsteady two-dimensional Navier-Stokes equations. Journal of Computational Physics 53: 209-226.

Chen, H.C., Patel, V.C. \& Ju, S. 1990. Solutions of ReynoldsAveraged Navier-Stokes equations for three-dimensional incompressible flows. Journal of Computational Physics 88(2): 305-336. 
Dixen, M., Sumer, B.M. \& Fredsøe, J. 2013. Numerical and experimental investigation of flow and scour around a halfburied sphere. Coastal Engineering 73: 84-105.

Escauriaza, C. \& Sotiropoulos, F. 2011. Initial stages of erosion and bed form development in a turbulent flow around a cylindrical pier. Journal of Geophysical Research 116: F03007.

Fortunado, A.B. \& Oliviera, A. 2007. Improving the stability of a morphodynamic modeling system. Journal of Coastal Research, Special Issue 50 (Proceedings of the 9th International Coastal Symposium, Gold Coast, Australia): 486 490.

Foti, S. \& Sabia, D. 2011. Influence of foundation scour on the dynamic response of an existing bridge. Journal of bridge engineering 16(2): 295-304.

Jia, Y., Yichun, X. \& Wang, S.S.Y. 2002. Numerical simulation of local scouring around a cylindrical pier. Proceedings of the $1^{\text {st }}$ International Conference on Scour of Foundations, College Station, Texas, USA.

Khosronejad, A., Kang, S., Borazjani, I. \& Sotiropoulos, F. 2011. Curvilinear immersed boundary method for simulating coupled flow and bed morphodynamic interactions due to sediment transport phenomena. Advances in Water Resources 34: 829-843.

Khosronejad, A., Kang, S. \& Sotiropoulos, F. 2012. Experimental and computational investigation of local scour around bridge piers. Advances in Water Resources 37: 7385.

Rodi, W. 1993. Turbulence models and their applications in hydraulics. $3^{\text {rd }} E d$., IAHR Monograph, Balkema, Rotterdam, The Netherlands.

Roulund, A., Sumer, B. M., Fredsøre, J. \& Michelsen, J. 2005. Numerical and experimental investigation of flow and scour aroud a circular pile. Journal of Fluid Mechanics 534: 351401.

Sumer, B.M., Baykal, C., Fuhrman, D.R., Jacobsen, N.G. \& Fredsøe, J. 2014. Numerical calculation of backfilling of scour holes. Proceedings of the 7th International Conference on Scour and Erosion, Perth, Australia.

Sumer, B.M. Petersen, T.U., Locatelli, L., Fredsøe, J., Musumeci, R.E. \& Foti, E. 2013. Backfilling of a scour hole around a pile in waves and current. Journal of Waterway, Port, Coastal, and Ocean Engineering 139: 9-23.

van Rijn, L.C. 1984. Sediment transport part III: Bed forms and alluvial roughness. Journal of Hydraulic Division 110(12): 1733-1754.

Wu, W, Rodi, W. \& Wenka, T. (2000). 3D numerical modeling of flow and sediment transport in open channels. Journal of Hydraulic Engineering 126(1): 4-15. 